\author{
Marquette University \\ e-Publications@Marquette
}

College of Nursing Faculty Research and

Publications

Nursing, College of

$10-2012$

\title{
Resilience in Family Members of Persons with Autism Spectrum Disorder: A Review of the Literature
}

\author{
Abir K. Bekhet \\ Marquette University, abir.bekhet@marquette.edu \\ Norah L. Johnson \\ Marquette University, norah.johnson@marquette.edu \\ Jaclene Zauszniewski \\ Case Western Reserve University
}

Follow this and additional works at: https://epublications.marquette.edu/nursing_fac

Part of the Nursing Commons

\section{Recommended Citation}

Bekhet, Abir K.; Johnson, Norah L.; and Zauszniewski, Jaclene, "Resilience in Family Members of Persons with Autism Spectrum Disorder: A Review of the Literature" (2012). College of Nursing Faculty Research and Publications. 316.

https://epublications.marquette.edu/nursing_fac/316 
Marquette University

e-Publications@Marquette

\title{
Nursing Faculty Research and Publications/College of Nursing
}

This paper is NOT THE PUBLISHED VERSION; but the author's final, peer-reviewed manuscript. The published version may be accessed by following the link in the citation below.

Issues in Mental Health Nursing, Vol. 33, No. 10 (2012): 650-656. DOI. This article is (C) Taylor \& Francis and permission has been granted for this version to appear in e-Publications@Marquette. Taylor \& Francis does not grant permission for this article to be further copied/distributed or hosted elsewhere without the express permission from Taylor \& Francis.

\section{Resilience in Family Members of Persons with Autism Spectrum Disorder: A Review of the Literature}

\author{
Abir K. Bekhet \\ College of Nursing, Marquette University, Milwaukee, WI \\ Norah L. Johnson \\ College of Nursing, Marquette University, Milwaukee, WI \\ Jaclene A. Zauszniewski \\ Bolton School of Nursing, Case Western Reserve University, Cleveland, $\mathrm{OH}$
}

\section{Abstract}

Worldwide, caregivers find caring for children with Autism Spectrum Disorder (ASD) challenging. Family members must manage many aspects of care giving, which is demanding, overwhelming, and can affect the family members' mental health. However learning how to be resilient may help family members overcome the stress and burden associated with caring for a person with ASD. A search was 
completed in Medline, PsycINFO, Proquest, Web of Science, and CINAHL using the key words "autism," "caregivers," "mothers," and "fathers," alone and in combination. Inclusion criteria were English language articles reporting studies with samples of children with ASD, as distinct from children with other intellectual or developmental disabilities. Fifty-eight articles that met these inclusion criteria were summarized and, from those, the authors selected 22 articles that included indicators of resilience. This integrative review highlights current research on resilience in adult family members of persons with ASD. Indicators of resilience, risk factors, protective factors, and outcomes of resilience were identified. The review indicates that parents of children with ASD who possess indicators of resilience are better able to manage the adversity associated with caring for children with ASD. Thus, enhancing resilience among family members of persons with autism may be beneficial to both the caregivers and care recipients.

Autism spectrum disorder (ASD) is a life-long neurodevelopmental disorder; onset generally occurs before age three, affecting a child's communication, social interactions, and behavior patterns (APA, 2000). Persons with ASD represent a significant proportion of the world population, making ASD a global health issue. While the World Health organization (WHO) does not report on the global prevalence of ASD specifically, its 2007 Global Burden of Disease report noted that persons with mental and neurological disorders, including ASD, account for almost $11 \%$ of the global disease burden (WHO, 2007). It is estimated that 1 out of every 110 Americans (2.8 million people) has ASD (Rice, 2009).

Throughout the world, caregivers find caring for children with ASD challenging. Family members must manage many aspects of caregiving, which is demanding, even overwhelming, and can affect family members' mental health (Baker, Blacher, \& Olsson, 2005; Johnson, Frenn, Feetham, \& Simpson, 2011; Phetrasuwan \& Miles, 2009). However, learning how to be resilient may help family members overcome the stress and burden associated with caring for a person with ASD (Van Breda, 2001). This integrative review highlights current research on resilience in adult family members of persons with ASD.

\section{THEORETICAL FRAMEWORK}

For years, resilience in children and adolescents was a focus of research (Garmezy \& Rutter, 1983; Werner \& Smith, 1992). Now, researchers have begun to study resilience in adults and caregivers. For example, Zauszniewski and colleagues (2010) looked at resilience in women family caregivers of adults with serious mental illness (Zauszniewski, Bekhet, \& Suresky, 2009) and, more recently, Bekhet and colleagues (2011) used resilience theory to examine the role of positive cognitions in Egyptian elders' relocation adjustment (Bekhet, Fouad, \& Zauszniewski, 2011). Different researchers have defined resilience differently, but all the definitions share the key characteristic of prevailing when faced with difficult and negative situations (Zauszniewski, Bekhet, \& Suresky, 2010).

Luthar and colleagues defined resilience as "a dynamic process encompassing positive adaptation within the context of significant adversity" (Luthar, Cicchetti, \& Becker, 2000, p. 545). It has also been defined as being resistant to stressful experiences (Rutter, 1999). Finally, Richardson (2002) has defined resilience as "The process of coping with adversity, change, or opportunity in a manner that 
result in the identification, fortification, and enrichment of resilient qualities or protective factors" (Richardson, 2002, p. 308).

According to resilience theory, an individual's resilience is determined by balancing risk and protective factors in the face of adversity (Luthar et al., 2000). The main constructs in resilience theory are risk factors, protective factors, indicators of resilience, and resilience outcomes.

\section{METHODS}

A search was completed in Medline, PsycINFO, Proquest, Web of Science, and CINAHL using the key words autism, caregivers, mothers, and fathers, alone and in combination. Inclusion criteria were English language articles reporting studies with samples of children with ASD, as distinct from children with other intellectual or developmental disabilities. Fifty-eight articles that met these inclusion criteria were summarized, and from those the authors selected the 22 descriptive articles that included indicators of resilience. In addition, there were only two intervention studies of parents/caregivers of persons with ASD addressing resilience and its indicators or risk and protective factors (Kasari et al., 2010; Okuno et al., 2011).

\section{RESULTS}

\section{Risk Factors}

Risk factors are those factors that predispose people to physical and mental health problems because they affect how a person adapts to stress (Greene, Galambos, \& Lee, 2003; Smith-Osborne, 2007). Risk factors for caregivers of persons with ASD include symptom severity, marital quality, parents' anger, and number of children with ASD.

Symptom severity has been identified as a risk factor in caring for persons with ASD (Allik, Larsson, \& Smedje, 2006; Benson \& Karlof, 2009; Ekas \& Whitman, 2010; Hartley, Barker, Seltzer, Greenberg \& Floyd, 2011). Ekas and Whitman (2010) looked at the relationship between symptom severity and social and emotional maternal outcomes in 119 American mothers of children aged 2 to 18 years old with ASD. They found that greater severity of symptoms was associated with poorer psychological well-being and life satisfaction, and a greater prevalence of depression (Ekas \& Whitman, 2010). Hartley and colleagues (Hartley et al., 2011) investigated the relationship between child symptoms and parenting experiences over time in 91 married mothers and fathers of adolescents and adults with ASD. Higher ratings of child symptoms were predictive of lower ratings of fathers' emotional closeness (Hartley et al., 2011). In addition, Benson and Karlof (2009) found a positive relationship between symptom severity and parents' depression in sample of 84 mothers and 6 fathers of 3-7 year olds. Finally, a study conducted in Sweden, found a negative relationship between maternal well-being and child behaviors in a sample of 31 mothers and 30 fathers of 32 children with ASD (Allik, Larsson, \& Smedje, 2006).

Marital quality has been identified as a risk factor that might compromise resilience in parents of children with ASD in two American studies and one Australian study (Brobst, Clopton, \& Hendrick, 2009; Hartley et al., 2011; Higgins, Bailey, \& Pearce, 2005). Brobst and colleagues compared 25 couples of children with ASD to 20 couples of typically developing children. Parents of children with ASD had less marital relationship satisfaction and experienced greater parenting stress (Brobst et al., 2009). 
Hartley and colleagues (Hartley et al., 2011) found that in a sample of 91 married mothers and fathers of adolescents and adults with ASD, those who had less marital satisfaction were more burdened by their adolescent and adult child with ASD over time than were parents with more marital satisfaction. In Australia, Higgins and colleagues found that 52 parents ( $97 \%$ mothers) with children with ASD had low marital satisfaction and low family functioning (adaptability and cohesion) (Higgins et al., 2005).

Two American studies have identified parents' anger as a factor that affected their emotional wellbeing (Benson \& Karlof, 2009; Carter, Martinez-Pedraza, \& Gray, 2009). The first study, conducted with 84 mothers and 6 fathers of persons with ASD aged 3-7 years old, found that anger was related to symptom severity, stress proliferation, and parental depression (Benson \& Karlof, 2009). The second study found a positive relationship between parental anger/hostile mood and depression severity in 143 mothers of toddlers with ASD (Carter, Martinez-Pedraza, \& Gray, 2009). In addition, a recent Israeli study found a positive relationship between marital quality and ability to cope with stress in a sample of 176 parents of children with ASD aged 6 through 16 (88 married couples) (Siman-Tov \& Kaniel, 2011).

Having more than one child with ASD has also been identified as a risk factor for mothers caring for children with ASD. Ekas and Whitman (2010) found a significant negative correlation between having more than one child with autism and lower life satisfaction, lower sense of well-being, greater negative affect, and higher incidents of depression.

\section{Protective Factors}

Protective factors promote resilience by diminishing the effects of risk and decreasing the negative reaction to it, thereby allowing caregivers to achieve positive outcomes (Rutter, 1987; Zauszniewski, Bekhet, \& Suresky, 2010). Protective factors in family members of children with autism include social support, age of the child, time since diagnosis, locus of control, cognitive appraisal, and religious beliefs and spirituality.

Social support has been identified as a protective factor in five American studies. Tobing and Glenwick (2006) found that satisfaction with social support was associated with low maternal distress in 97 American mothers of children with ASD aged 2 to 18 years. Similarly, Ekas, Lickenbrock, and Whitman (2010) found that family support was associated with lower levels of maternal depression, stress, and negative affect in 119 American mothers of children with ASD (Ekas, Lickenbrock, \& Whitman, 2010). Also, in a sample of 53 mothers and 23 fathers of American children with ASD aged 21 and under $(M=$ 8; $S D=4$ ), Hall and Graff (2011) found that their spouses and partners were greater sources of support than social clubs or groups and that this support was positively correlated with parenting stress and ability to cope with the children (Hall \& Graff, 2011). Similarly, Brobst and colleagues found that social support was negatively correlated with parenting stress and positively correlated with relationship satisfaction in a sample of 25 couples who were parents of children with autism (Brobst, Clopton, \& Hendrick, 2009). Finally, Carter and colleagues (2009) found that perception of the availability of social support was negatively correlated with depression severity. An Australian study found that social support buffered the effects of stress on parents' well-being if those providing the social support were perceived as competent (Sharpley, Bitskia, \& Efremidis, 1997). In addition, an Israeli study found a positive relationship between social support and coping with parental stress in a sample of 176 parents (88 married couples) of children with ASD aged 6 through 16 (Siman-Tov \& Kaniel, 2011). Finally, a 
qualitative study conducted in America that included eight Southeast Asian immigrant mothers of children with ASD aged 3 to 10 years of age found that school support was the greatest supportive entity (Luong, Yoder, \& Canham, 2009).

Age of the child has been identified as another protective factor for caregivers of a child with ASD. A study by Ekas and Whitman (2010) found that mothers of older children perceived less stress related to their child's challenging behaviors than mothers of younger children. Hartley et al., 2011, found a significant negative relationship between the child's age and parenting burden; that is to say, parents with older children reported less burden.

Time since diagnosis has been identified as a protective factor. A study by Kuhn and Carter (2006) found that time since diagnosis was positively significantly correlated with maternal self-efficacy in 170 mothers of children with ASD (Kuhn \& Carter, 2006).

Locus of control has been defined as the sense of control over events, either by internal factors such as one's own behavior or by external factors such as other people's actions, luck, fate, or chance (Rotter, 1966). Research has found that people with an internal locus of control deal with stressful situations more easily than those with an external locus of control (Rotter, 1966). A recent study conducted in Israel by Siman-Tov and Kaniel (2011) found a positive relationship between internal locus of control and coping with parental stress in a sample of 176 parents ( 88 married couples) of children with ASD aged 6 through 16.

Changing cognitive appraisal involves changing the way one views or makes sense of a situation by using positive reinterpretation, and finding meaning, acceptance, and humor (Terry \& Hynes, 1998). A study conducted by Tunali and Power (2002) found that in a sample of 58 mothers of children, aged 5 to 15 years old, with and without autism (29 mothers in each group), those who used positive cognitive appraisal showed the greatest life satisfaction.

A study by Ekas, Whitman \& Shivers (2009) also found that religious beliefs, activities, and spirituality acted as protective factors against socioemotional functional problems, including depression and low self-esteem in a sample of 119 American mothers of children with ASD younger than 18 years old. Similarly, in a qualitative study of seven parents of children with ASD, aged 3-10, with moderate to severe levels of disability, Luong, Yoder, and Canham (2009) found that religious practices such as praying at home "recharged their hope" (Luong et al., 2009).

\section{Indicators of Resilience}

Indicators of resilience are predictors of resilience. Indicators of resilience in family members of children with ASD include self-efficacy, acceptance, sense of coherence, optimism, positive family functioning, and enrichment.

Self-efficacy refers to a persons' confidence in their ability to succeed when approaching goals, tasks, and challenges (Bandura, 1977; 1995). Self-efficacy may affect psychological states as well as motivation and behavior. In family members of persons with ASD, greater self-efficacy has been associated with better management of stress (Kuhn, 2006). Two studies have investigated self-efficacy in American family members of persons with ASD (Carter, Martinez-Pedraza, \& Gray, 2009; Kuhn \& Carter, 2006). Carter and colleagues (2009) looked at factors contributing to depressive symptoms and 
stress over time and their relationships to self-efficacy in 143 mothers of toddlers with ASD. The sample was $92 \%$ white, $2 \%$ Hispanic (Latino), 4\% Asian, 1\% Black/African American, and 2\% more than one race. Ninety-two of the 143 mothers completed three data collections. The findings indicated that lower parenting efficacy predicted depression over time. Kuhn and Carter (2006) examined the relationship between maternal self-efficacy and parenting cognitions among 170 mothers of children with autism. Twelve percent of the participants self-identified as members of ethnic minorities. Participants reported a high socioeconomic status. Agency, or being actively engaged with the child, was positively correlated with maternal self-efficacy. Guilt, maternal depression, and parenting stress were negatively correlated with maternal self-efficacy.

Acceptance has been defined as the ability to embrace internal events such as thoughts, feelings, memories, and sensations (Orsillo, Roemer, Block-Lerner, \& et al., 2004). Acceptance involves adjustment and adaptation to a child's disability and abilities to find peace in the present (Luong, Yoder, \& Canham, 2009); it is an active process of understanding the chronic nature of an unchangeable situation (Orsillo et al., 2004). Three studies have discussed the role of acceptance in family members of persons with autism (Bayat, 2007; Luong et al., 2009; Oppenheim et al., 2009). The first looked at the effects of autism on family coping styles, including acceptance, and on support systems among nine first-generation Southeast Asian parents of children, 3-10 years old, with ASD. Acceptance was one of the coping style patterns that helped parents be more resilient over time (Luong et al., 2009). A second study, by Bayat (2007), investigated resilience in a sample of 175 American families of children, 2-18 years old, with autism; $63 \%$ were Whites, $16 \%$ were African American, and the others were Hispanic, Asian, or other. Three questions asked about the positive and the negative effects of ASD on the family as well as on the participant's personal life. Acceptance helped the parents change their world view and recognize what they had, instead of what they were missing (Bayat, 2007). The third study investigated the relationship between insightfulness and resolution (or acceptance of diagnosis) to secure child attachment among Israeli mothers of children, 32-69 months of age, with autism (Oppenheim et al., 2009). The study found a positive association between being insightful and resolved and having securely attached children.

Sense of coherence may be defined as cognitive, behavioral, and motivational skills that reflect the view that the world is manageable, comprehensible, and meaningful (Antonovsky, 1979). Only one study has examined the relationship of sense of coherence and coping to stress among mothers and fathers of children with autism (Pisula \& Kossakowska, 2010). That study compared the sense of coherence of 26 Polish parent dyads of 3 to 7 year-old children with ASD to sense of coherence in 29 Polish biological parent dyads with typically developing children. The parents of children with autism had a lower sense of coherence than the parent dyads with typically developing children, and this, in turn, contributed to negative coping strategies, such as not seeking social support and not accepting responsibility. The authors concluded that interventions for parents of children with autism are needed to strengthen their sense of coherence and act as a moderator between parental stress and coping (Pisula \& Kossakowska, 2010). A recent Israeli study also found a positive relationship between sense of coherence and coping with parental stress in a sample of 176 parents (88 married couples) of children, aged 6 through 16, with ASD (Siman-Tov \& Kaniel, 2011). 
A few studies have examined the role of optimism in family members of persons with ASD. A study by Ekas, Lickenbrock, and Whitman (2010), which included 119 mothers of children with autism younger than 18 years of age, found that family support was associated with increased optimism, and this led to fewer negative maternal outcomes, such as stress and depression. A second study, by Greenberg and colleagues (2004), included 102 mothers of adults with ASD with an average age of 34 . This study found that optimism mediated the association between the quality of the mother's relationship to her adult child with ASD and her psychological/physical well-being (Greenberg, Seltzer, Krauss, Chou, \& Hong, 2004). Kuhaneck and colleagues (2010) also found that optimism or joy led to effective coping in a sample of 11 mothers of children, aged 6 to 11 years old, with ASD.

Positive family functioning involves a commitment to support the functions of the family including economics, safety, child rearing, caregiving, and communication. It requires joint efforts to manage family responsibilities (Feetham, 2007; Knafl \& Deatrick, 2003). A recent study by Johnson and colleagues (2011) investigated the mediating effects of positive family functioning on the relationship between parenting stress and mental and physical health in sample of 64 parent dyads of American children, aged 2-24 years, with autism. Positive family functioning mediated the effect of stress on mental health (Johnson, Frenn, Feetham, \& Simpson, 2011).

Yatchmenoff and colleagues (1998) have defined enrichment as having a positive view of oneself as a parent, having positive relationships with children and partners, and living a religious or spiritual life. Enrichment was studied by Phelps and colleagues (2009) in 80 caregivers of persons with ASD; they found an inverse relationship between parenting stress and enrichment. In their study, $97.5 \%$ of the caregivers were mothers of persons with ASD who ranged in age from 3 to 35 years with a mean of 10.75 years $(S D=6.53)$.

\section{Outcomes of Resilience}

Resilience and its indicators have been found to be associated with many positive health outcomes (Van Breda, 2001). In parents with ASD, resilience indicators have been associated with positive indicators of parental mental health, including less depression (Carter et al., 2009; Ekas et al., 2010; Siman-Tov \& Kaniel, 2011; Tobing \& Glenwick, 2006), better marital quality (Siman-Tov \& Kaniel, 2011), greater psychological well-being (Kuhn \& Carter, 2006), and greater life satisfaction (Ekas \& Whitman, 2010).

In a study of 143 mothers of toddlers with ASD, Carter and colleagues (2009) found that greater parenting efficacy predicted lower depression. Ekas and Whitman (2010) found that less severity of children's symptoms was associated with greater psychological well-being and life satisfaction and less depression. In addition, Tobing and Glenwick (2006) found that satisfaction with social support was associated with low maternal distress in sample of 97 American mothers of children with ASD aged 218 years. Similarly, a study conducted by Kuhn and Carter (2006) found that maternal self-efficacy, an indicator of resilience, was associated with less maternal depression and parenting stress. Also, SimanTov and Kaniel (2011), found a positive relationship between marital quality and ability to cope with stress. 


\section{Resilience Intervention Studies}

There were only two intervention studies of parents or caregivers of persons with ASD addressing resilience and its indicators or risk and protective factors (Kasari et al., 2010; Okuno et al., 2011). The first study tested the effectiveness of a modified parent training program on parental confidence and children's behavior in a sample of 14 mothers of preschool-age children with ASD (Okuno et al., 2011). The intervention consisted of six sessions and was completed in three months. Findings indicated that the program was effective in improving parents' confidence and decreasing children's challenging behaviors. The second intervention study was conducted to determine whether a joint engagement intervention would increase joint engagement between caregivers and toddlers with ASD (Kasari et al., 2010). The intervention consisted of 24 caregiver-mediated sessions with follow-up one year later. The study found significantly greater improvements in joint engagement among caregivers who participated in the program than among a control group. Furthermore, the improvements were maintained one year later. These are among the first data to suggest that short-term parent-mediated interventions can have important effects on core impairments in toddlers with ASD.

\section{DISCUSSION}

Given the increasing prevalence of ASD (Rice, 2009) and its impact on the family who play a major role in managing caregiving (Siman-Tov \& Kaniel, 2011; Smith et al., 2010), it is important to pay more attention to this vulnerable population. While resilience has been examined among parents of children with autism, the majority of the caregivers that were studied were mothers (Carter et al., 2009; Ekas \& Whitman, 2010; Kuhaneck et al., 2010; Kuhn \& Carter, 2006; Luong et al., 2009). Yet, studies found a relationship between marital quality and indicators of resilience (Brobst, Clopton, \& Hendrick, 2009; Hartley et al., 2011; Higgins, Bailey, \& Pearce, 2005); therefore, future studies should include both parents.

Some studies have addressed the role of resilience in affecting psychological outcomes. Only two intervention studies of parents/caregivers of persons with ASD have addressed resilience and its indicators or risk and protective factors (Kasari et al., 2010; Okuno et al., 2011).

The 22 studies reviewed here show that parents of children with ASD who possess indicators of resilience are better able to manage the adversity associated with caring for children with ASD. Thus, enhancing resilience among family members of persons with autism may be beneficial to both the caregivers and care recipients.

According to resilience theory, resilience is determined by balancing risk and protective factors in the face of adversity (Luthar et al., 2000). In fact, although individuals may have little control over risk factors, such as severity of symptoms, and number of children with ASD, it is definitely possible to strengthen their protective factors. This can be achieved through interventions designed to increase positive cognitions or cognitive appraisal and by providing support for family caregivers of persons with ASD. This, in fact, will result in greater resilience among caregivers of persons with ASD, which may be recognized in such indicators as self-efficacy, acceptance, sense of coherence, optimism, resourcefulness, and positive family functioning that will, in turn, affect the care recipient.

Given the importance of resilience, nursing interventions need to be developed to enhance resilience among parents of children with ASD. Longitudinal studies also are needed to determine the lagged and 
extended effects of resilience on physical and psychological outcomes of persons with ASD. A recent study of 88 parent dyads found a positive significant relationship between parental stress and severity of symptoms in child autism (Siman-Tov \& Kaniel, 2011). Therefore, managing the stress of the parents and enhancing their psychological well-being may also have an impact on the child's symptoms. Future research should examine the effects of financial burden, resulting from balancing stresses and strains arising from their workplace, family life, and caregiving roles, on caregivers' well-being.

Research also has shown a negative relationship between the child's symptom severity and parental stress (Allik, Larsson, \& Smedje, 2006; Benson \& Karlof, 2009; Ekas \& Whitman, 2010; Hartley et al., 2011). In a vicious cycle, the child's severity of symptoms increases maternal stress which, in turn, increases the child's symptoms. Interventions that target the caregivers could help to disrupt this vicious cycle and improve the psychological and physical well-being of both caregivers and the care recipient.

\section{REFERENCES}

Allik, H., Larsson, J., \& Smedje, H. (2006). Health-related quality of life in parents of school-age children with Asperger syndrome or high-functioning autism. Health and Quality of Life Outcomes, 4, 1. doi: 10.1186/1477-7525-4-1

American Psychiatric Association. (2000). Diagnostic and statistical manual of mental disorders (4th ed., text rev.). Washington, DC: Author.

Antonovsky A. (1979). Health, stress, and coping. San Francisco, CA: Jossey-Bass.

Baker, B., Blacher, J., \& Olsson, M. (2005). Preschool children with and without developmental delay: Behaviour problems, parents' optimism, and well-being. Journal of Intellectual Disability Research, 49(Part 8), 575590.

Bandura, A. (1977). Self-efficacy: Toward a unifying theory of behavioral change. Psychological review, 84(2), 191-215.

Bandura, A. (1995). Self-efficacy in changing societies. Cambridge, UK: Cambridge University Press.

Bayat, M. (2007). Evidence of resilience in families of children with autism. Journal of Intellectual Disability Research, 51, 702-714. doi: 10.1111/j.1365-2788.2007.00960.x

Bekhet, A. K., Fouad, R., \& Zauszniewski, J. A. (2011). The role of positive cognitions in Egyptian elders' relocation adjustment. Western Journal of Nursing Research, 33(1), 121-135. doi: 10.1177/0193945910381763

Benson, P. R., \& Karlof, K. L. (2009). Anger, stress proliferation, and depressed mood among parents of children with ASD: A longitudinal replication. Journal of Autism and Developmental Disorders, 39(2), 350-362. doi: 10.1007/s10803-008-0632-0

Brobst, J. B., Clopton, J. R., \& Hendrick, S. S. (2009). Parenting children with autism spectrum disorders: The couple's relationship. Focus on Autism and Other Developmental Disabilities, 24(1), 38-49. doi: $10.1177 / 1088357608323699$

Carter, A. S., Martinez-Pedraza, F. D. L., \& Gray, S. A. O. (2009). Stability and individual change in depressive symptoms among mothers raising young children with ASD: Maternal and child correlates. Journal of Clinical Psychology, 65(12), 1270-1280. doi: 10.1002/jclp.20634

DeGrace, B. (2004). The everyday occupation of families with children with autism. American Journal of Occupational Therapy, 58(5), 543-550.

Ekas, N. V., Lickenbrock, D. M., \& Whitman, T. L. (2010). Optimism, social support, and well-being in mothers of children with autism spectrum disorder. Journal of Autism and Developmental Disorders, 40(10), 12741284. doi: 10.1007/s10803-010-0986-y

Ekas, N., \& Whitman, T. L. (2010). Autism symptom topography and maternal socioemotional functioning. AJIDD: American Journal on Intellectual and Developmental Disabilities, 115(3), 234-249. doi: 10.1352/19447558-115.3.234 
Ekas, N. V., Whitman, T. L., \& Shivers, C. (2009). Religiosity, spirituality, and socioemotional functioning in mothers of children with autism spectrum disorder. Journal of Autism and Developmental Disorders, 39(5), 706-719. doi: 10.1007/s10803-008-0673-4

Feetham, S. L. (2005). Family nursing: Challenges and opportunities: Providing leadership in family nursing from local to global health. Journal of Family Nursing, 11(4), 327-331.

Garmezy, N., \& Rutter, M. (1983). Stress, coping, and development in children. New York, NY: McGraw-Hill.

Greene, R. R., Galambos, C. \& Lee, Y. (2003). Resilience theory: Theoretical and professional conceptualizations. Journal of Human Behavior and the Social Environment, 8(3), 75-91.

Greenberg, J., Seltzer, M., Krauss, M., Chou, R., \& Hong, J. (2004). The effect of quality of the relationship between mothers and adult children with schizophrenia, autism, or Down Syndrome on maternal wellbeing: The mediating role of optimism. American Journal of Orthopsychiatry, 74(1), 14-25. doi: 10.1037/0002-9432.74.1.14

Hall, H. R., \& Graff, J. C. (2011). The relationships among adaptive behaviors of children with autism, family support, parenting stress, and coping. Issues in Comprehensive Pediatric Nursing, 34(1), 4-25. doi: 10.3109/01460862.2011.555270

Hartley, S. L., Barker, E. T., Seltzer, M. M., Greenberg, J. S., \& Floyd, F. J. (2011). Marital satisfaction and parenting experiences of mothers and fathers of adolescents and adults with autism. AJIDD-American Journal on Intellectual and Developmental Disabilities, 116(1), 81-95. doi: 10.1352/1944-7558-116.1.81

Higgins, D., Bailey, S., \& Pearce, J. (2005). Factors associated with functioning style and coping strategies of families with a child with an autism spectrum disorder. Autism, 9(2), 125-137. doi: $10.1177 / 1362361305051403$

Johnson, N., Frenn, M., Feetham, S., \& Simpson, P. (2011). Autism spectrum disorder: Parenting stress, family functioning and health-related quality of life. Families Systems \& Health, 29(3), 232-252. doi: $10.1037 / \mathrm{a} 0025341$

Kasari, C., Gulsrud, A. C., Wong, C., Kwon, S., \& Locke, J. (2010). Randomized controlled caregiver mediated joint engagement intervention for toddlers with autism. Journal of Autism and Developmental Disorders, 40(9), 1045-1056. doi: 10.1007/s10803-010-0955-5

Kasari, C., \& Sigman, M. (1997). Linking parental perceptions to interactions in young children with autism. Journal of Autism and Developmental Disorders, 27(1), 39-57. doi: 10.1023/A:1025869105208

Knafl, K., \& Deatrick, J. (2003). Further refinement of the family management style framework. Journal of Family Nursing, 9, 232-256.

Kuhaneck, H. M., Burroughs, T., Wright, J., Lemanczyk, T., \& Darragh, A. R. (2010). A qualitative study of coping in mothers of children with an autism spectrum disorder RID E-2946-2011. Physical \& Occupational Therapy in Pediatrics, 30(4), 340-350. doi: 10.3109/01942638.2010.481662

Kuhn, J. C., \& Carter, A. S. (2006). Maternal self-efficacy and associated parenting cognitions among mothers of children with autism. American Journal of Orthopsychiatry, 76(4), 564-575. doi: 10.1037/00029432.76.4. 564

Lloyd, T., \& Hastings, R. P. (2009). Parental locus of control and psychological well-being in mothers of children with intellectual disability. Journal of Intellectual \& Developmental Disability, 34(2), 104-115. doi: 10.1080/13668250902862074

Luong, J., Yoder, M. K., \& Canham, D. (2009). Southeast Asian parents raising a child with autism: A qualitative investigation of coping styles. Journal of School Nursing, 25(3), 222-229. doi: 10.1177/1059840509334365

Luthar, S., Cicchetti, D., \& Becker, B. (2000). The construct of resilience: A critical evaluation and guidelines for future work. Child Development, 71, 543-562.

Okuno, H., Nagai, T., Sakai, S., Mohri, I., Yamamoto, T., Yoshizaki, A., ... Taniike, M. (2011). Effectiveness of modified parent training for mothers of children with pervasive developmental disorder on parental confidence and children's behavior. Brain \& Development, 33(2), 152-160. doi:

10.1016/j.braindev.2010.03.007 
Oppenheim, D., Koren-Karie, N., Dolev, S., \& Yirmiya, N. (2009). Maternal insightfulness and resolution of the diagnosis are associated with secure attachment in preschoolers with autism spectrum disorders RID E3201-2010. Child Development, 80(2), 519-527. doi: 10.1111/j.1467-8624.2009.01276.x

Orsillo, S. M., Roemer, L., Block-Lerner, J., \& et al. (2004). Acceptance, mindfulness, and cognitive-behavioral therapy: Comparisons, contrasts and applications to anxiety. In S. C. Hayes, V. M. Follette, M. M. Linehan (Eds.), Mindfulness and acceptance: Expanding the cognitive-behavioral tradition (pp. 66-95). New York, NY: Guilford.

Phelps, K. W., McCammon, S. L., Wuensch, K. L., \& Golden, J. A. (2009). Enrichment, stress, and growth from parenting an individual with an autism spectrum disorder. Journal of Intellectual \& Developmental Disability, 34(2), 133-141. doi: 10.1080/13668250902845236

Phetrasuwan, S., \& Miles, M. (2009). Parenting stress in mothers of children with autism spectrum disorders. Journal of Pediatric Nursing, 14(3), 157-165.

Pisula, E., \& Kossakowska, Z. (2010). Sense of coherence and coping with stress among mothers and fathers of children with autism. Journal of Autism and Developmental Disorders, 40(12), 1485-1494. doi: 10.1007/s10803-010-1001-3

Richardson, G. E. (2002). The metatheory of resilience and resiliency. Journal of Clinical Psychology, 58(3), 307321.

Rice, C. (2009). Prevalence of autism spectrum disorders-Autism and Developmental Disabilities Monitoring Network, United States, 2006. CDC MMWR Surveillance Summaries, 58(SS-10). Retrieved from http://www.cdc.gov/mmwr/preview/mmwrhtml/ss5810a1.htm

Rotter, J. B. (1966). Generalized expectancies for internal versus external control of reinforcement. Psychological Monographs: General and Applied, 80(1), 1-28.

Rutter, M. (1987). Psychosocial resilience and protective mechanisms. The American Journal of Orthopsychiatry, $57,316-31$.

Rutter, M. (1999). Resilience concepts and findings: Implications for family therapy. Journal of Family Therapy, 2, 119-144.

Sharpley, C. F., Bitsika, V., \& Efremidis, B. (1997). Influence of gender, parental health, and perceived expertise of assistance upon stress, anxiety, and depression among parents of children with autism. Journal of Intellectual \& Developmental Disability, 22(1), 19-28.

Siman-Tov, A., \& Kaniel, S. (2011). Stress and personal resource as predictors of the adjustment of parents to autistic children: A multivariate model. Journal of Autism and Developmental Disorders, 41(7), 879-890. doi: 10.1007/s10803-010-1112-x

Smith, L. E., Hong, J., Seltzer, M. M., Greenberg, J. S., Almeida, D. M., \& Bishop, S. L. (2010). Daily experiences among mothers of adolescents and adults with autism spectrum disorder. Journal of Autism and Developmental Disorders, 40(2), 167-178. doi: 10.1007/s10803-009-0844-y

Smith-Osborne, A. (2007). Life span and resiliency theory: a critical review. Advances in Social Work, 8(1), 15268.

Terry, D., \& Hynes, G. (1998). Adjustment to a low-control situation: Reexamining the role of coping responses. Journal of Personality and Social Psychology, 74(4), 1078-1092. doi: 10.1037//0022-3514.74.4. 1078

Tobing, L. E., \& Glenwick, D. S. (2006). Predictors and moderators of psychological distress in mothers of children with pervasive development disorders. Journal of Family Social Work, 10(4), 1-22.

Tunali, B., \& Power, T. (2002). Coping by redefinition: Cognitive appraisals in mothers of children with autism and children without autism. Journal of Autism and Developmental Disorders, 32(1), 25-34. doi: 10.1023/A:1017999906420

Van Breda, A. D. (2001). Resilience theory: A literature review. Pretoria: South Africa: South African Military Health Service.

Werner, E. E., \& Smith, R. S. (1992). Overcoming the odds: High risk children from birth to adulthood. Ithaca, NY: Cornell University Press.

Woodgate, R. L., Ateah, C., \& Secco, L. (2008). Living in a world of our own: The experience of parents who have a child with autism. Qualitative Health Research, 18(8), 1075-1083. doi: 10.1177/1049732308320112 
World Health Organization. (2007). Global Burden of Disease Report. Retrieved from http://www.who.int/mental health/neurology/en/

Yatchmenoff, D. K., Koren, P. E., Friesen, B. J., Gordon, L. M., \& Kinney, R. F. (1998). Enrichment and stress in families caring for a child with a serious emotional disorder. Journal of Child \& Family Studies, 7(2), 129145.

Zauszniewski, J. A., Bekhet, A. K., \& Suresky, M. J. (2009). Effects on resilience of women family caregivers of adults with serious mental illness: The role of positive cognitions. Archives of Psychiatric Nursing, 23(6), 412-422. doi: 10.1016/j.apnu.2008.12.004

Zauszniewski, J. A., Bekhet, A. K., \& Suresky, M. J. (2010). Resilience in family members of persons with serious mental illness. Nursing Clinics of North America, 45(4), 613. doi: 10.1016/j.cnur.2010.06. 007 